\title{
Water Flow Through the Polypropylene-Based Geotextiles
}

\author{
Asis Patanaik, ${ }^{1,2}$ Rajesh D. Anandjiwala ${ }^{1,2}$ \\ ${ }^{1}$ CSIR Materials Science and Manufacturing, Fibers and Textiles Competence Area, Port Elizabeth 6000, South Africa \\ ${ }^{2}$ Department of Textile Science, Faculty of Science, Nelson Mandela Metropolitan University, Port Elizabeth 6031, \\ South Africa
}

Received 5 December 2007; accepted 19 January 2008

DOI 10.1002/app.28050

Published online 12 March 2008 in Wiley InterScience (www.interscience.wiley.com).

\begin{abstract}
This article presents the results from a study on the cross-plane water flow through the needle punched nonwoven geotextiles produced from polypropylene fibers. Different types of nonwoven geotextiles are produced by varying the processing parameters during the needle punching process. The pore characteristics and the crossplane water flow (or permeability) through the nonwoven geotextiles are measured by liquid extrusion porometry and water permeability tester, respectively. The water flow
\end{abstract}

velocities through the geotextiles are predicted by the finite element analysis. There is a good correlation between the average velocity data obtained from water permeability test and theoretical prediction based on finite element analysis. The pore characteristics play an important role in water permeability behavior of nonwoven geotextiles. (c) 2008 Wiley Periodicals, Inc. J Appl Polym Sci 108: 3876-3880, 2008

Key words: fibers; modeling; orientation; structure

\section{INTRODUCTION}

The cross-plane water flow (or permeability) through the nonwoven fabrics plays an important role in many applications such as medical and hygiene, filtration, composite manufacturing, etc. Nonwoven geotextiles are fibrous structures capable of doing more than one functions simultaneously, i.e., separation, filtration, and drainage. The distinctive porous structure of nonwoven geotextiles makes them ideal medium for liquid filtration and drainage applications in comparison with their woven counterpart because of the low cost of production and product can be manufactured in a very short time. The polypropylene fiber based nonwoven geotextiles offer further advantages due to their chemical inertness, low water absorption and quick drying capacity, which makes them ideal for liquid filtration and drainage applications. The water permeability behavior of nonwoven geotextiles is mainly influence by the pore characteristics namely, pore size and its distribution. The performance characteristics of nonwoven geotextiles are determined by the way water flow through it. Ideally, there should be a smooth flow of water, so that unnecessary pressure build-up can be avoided. Therefore, the pore characteristics influence the water permeability behavior. The orientation of fibers in nonwovens varies from regions to regions due to dif-

Correspondence to: A. Patanaik (patnaik_asis@yahoo.com).

Journal of Applied Polymer Science, Vol. 108, 3876-3880 (2008) C 2008 Wiley Periodicals, Inc.

\section{(\$)WILY}

InterScience ferent structural arrangement of fibers. ${ }^{1-3}$ It also affects the water permeability behavior.

Different processing parameters during needle punching may results in different structural arrangement of fibers in nonwoven geotextiles and subsequently affecting the pore characteristics. There may be a different arrangement of pores in nonwoven geotextiles, when the depth of needle penetration is varied during needle punching process, keeping the fabric area weight (mass per unit area, $\mathrm{g} / \mathrm{m}^{2}$ ) constant. The reported research works on this important aspect are scanty, so, we attempt to link the changes in pore characteristics with the measured permeability values of nonwoven geotextiles. This work focuses on the cross-plane water flow through the polypropylene fiber based nonwoven geotextiles. It is often assumed to be laminar ${ }^{4,5}$ and laminar flow through anisotropic nonwoven geotextiles can be described by the Darcy's law ${ }^{6,7}$ as:

$$
v=-\frac{k}{\eta}\left(\frac{d p}{d x}\right)
$$

where $v$ is the volume flow rate of the fluid in a unit area, $\eta$ is the liquid viscosity, $d p$ is the difference in hydraulic pressure, $d x$ is the conduit distance, and $k$ is the specific permeability. In practical applications of Darcy's law, it is preferable to use the permeability coefficient, $K$, which is also known as Darcy's coefficient. This coefficient $(K)$ is defined in Darcy's law as: $v=K \times i$, where $i$ is the hydraulic gradient. ${ }^{8}$ The above coefficient $(K)$ normally represents the permeability of the porous medium. 
The finite element analysis (FEA) is used for modeling and simulating wide range of technical problems. For the present work, it was performed by the commercially available software Comsol Multiphysics. ${ }^{9}$ Different types of fiber orientations were considered in the two dimensional-2D FEA of nonwoven geotextiles and water flow velocity through it were computed. The water permeability was measured experimentally by water permeability tester. The pore characteristics were measured experimentally by liquid extrusion poromerty. The water flow velocities data obtained from the instrument and FEA are compared.

\section{EXPERIMENTAL}

\section{Sample preparation}

Needle punched nonwoven geotextiles are produced by subjecting the polypropylene fibers to carding, then orienting the carded web in the cross direction by using a cross lapper, subsequently subjecting it to the action of barbed needles in needle punching machine. The length and fineness of fibers utilized for sample preparation are $60 \mathrm{~mm}$ and 6.6 dtex, respectively. The crimp and average diameter of the fibers are found to be $10 / \mathrm{cm}$ and $17 \mu \mathrm{m}$, respectively. The following processing parameters during needle punching were used for producing the nonwoven geotextiles: feeding speed, $0.7 \mathrm{~m} / \mathrm{min}$; depth of needle penetration, 4,6 , and $8 \mathrm{~mm}$; stroke frequency, 256/min; and output speed, $4 \mathrm{~m} / \mathrm{min}$. The nominal area density of the nonwoven geotextiles was $120 \mathrm{~g} / \mathrm{m}^{2}$.

\section{Measurement of water permeability}

The water permeability test is carried out by the Permeameter GE-TE-FLOW-K instrument. The measuring principle of this instrument is based on falling hydraulic head method in according to EN ISO 11058 standards. ${ }^{10}$ In falling head method, a column of water is introduced normal to the geotextiles plane to induce a laminar flow through its structure. The temperature of the water is maintained at $20^{\circ} \mathrm{C}$. The water flow rate and the pressure change against time are taken to measure the permeability. The test is carried out without adding any weight to the sample with a diameter of $67.8 \mathrm{~mm}$. The measuring range of the Permeameter GE-TE-FLOW-K contains hydraulic difference in height of $0<H<540 \mathrm{~mm}$.

\section{Measurement of pore size and its distribution}

For the present work, the capillary flow porometer was used to characterize the pore structure of nonwoven geotextiles, principle of which is based on the liquid extrusion porometry technique. ${ }^{11}$ In this technique, a wetting liquid with known surface tension of 15.9 dynes/cm fills the pores spontaneously and it is then removed by pressurized nonreacting gas (air) to give pore size and its distribution. Three kinds of pores may be present in nonwoven geotextiles, namely, closed pores, through pores, and blind pores. Closed pores are not accessible and therefore do not allow passage of liquid and air. The blinds pores terminate inside the material and do not permit the fluid flow. Through pores are open and allow the flow through the medium and they are important for filtration and drainage applications. ${ }^{12}$ The important pore structure characteristics of nonwoven filter media are the most constricted through pore diameter (smallest detected pore diameter), the largest pore diameter (bubble point pore diameter), and mean pore diameter (mean flow pore diameter). Mean flow pore diameter is the diameter of the majority of the pores. ${ }^{13}$ It is defined as half of the flow through the pores having diameter greater than mean flow pore diameter and other half of the flow is through the pores having diameter smaller than mean flow pore diameter. ${ }^{12,14}$

\section{Measurement of fiber orientation}

The fiber orientation is measured by using image analysis program "Analysis" version 3.2. The relative frequency of fibers for $10^{\circ}$ orientation interval with respect to cross direction is computed.

\section{FINITE ELEMENT ANALYSIS}

The FEA is a tool to build complex model with simple elements. The complex model is divided into a number of manageable elements. The system is then described by the physical properties of each element. These elements are connected to their neighbors by nodes. This forms an approximate system of equations for the entire structure. In the next step, the system of equations is solved involving unknown quantities at the nodes. After the solution, the desired quantities at selected elements can be calculated. For the present work, velocity inlet and outlet boundary conditions with no slip at wall are taken into account and following assumptions are considered:

a. Fibers are assumed as long circular cylinders.

b. Fiber crimp is considered.

c. Thickness of fabric is very small compared with other two dimensions.

Modeling approach based on assuming a single fiber as cylindrical rod is adopted in this study. The representation of fibers by a single element allows a 
TABLE I

Various Dimensional Parameters, Pore Size, and Permeability Behavior of Needle-Punched Polypropylene Fiber-based Nonwoven Geotextiles

\begin{tabular}{|c|c|c|c|c|c|c|c|c|}
\hline \multirow{2}{*}{$\begin{array}{l}\text { Sample } \\
\text { code }\end{array}$} & \multirow{2}{*}{$\begin{array}{l}\text { Thickness } \\
(\mathrm{mm})\end{array}$} & \multicolumn{3}{|c|}{ Pore diameter $(\mu \mathrm{m})$} & \multirow{2}{*}{$\begin{array}{c}\text { Permeability } \\
K_{20}\left(\mathrm{~m} / \mathrm{s} \times 10^{-2}\right)\end{array}$} & \multirow{2}{*}{$\begin{array}{l}\text { Velocity }^{\mathrm{a}} \\
(\mathrm{mm} / \mathrm{s})\end{array}$} & \multirow{2}{*}{$\begin{array}{l}\text { Velocity } \\
\text { (mm/s) }\end{array}$} & \multirow[b]{2}{*}{$R^{2}$} \\
\hline & & Smallest & Mean flow & Maximum & & & & \\
\hline $\mathrm{A} 1^{\mathrm{c}}$ & 2.4 & 53.37 & 215.62 & 367.81 & 1.25 & 125 & 105 & 0.84 \\
\hline A2 & 2.0 & 40.51 & 189.10 & 331.73 & 1.09 & 109 & 93 & 0.87 \\
\hline A3 & 1.7 & 24.64 & 163.23 & 291.12 & 0.97 & 97 & 80 & 0.85 \\
\hline
\end{tabular}

a Average velocity measured from water permeability tester.

${ }^{\mathrm{b}}$ Average velocity obtained from FEA.

${ }^{\mathrm{c}}$ Needle depth: A1, $4 \mathrm{~mm}$; A2, $6 \mathrm{~mm}$; and A3, $8 \mathrm{~mm}$.

significant reduction in computation time. The behavior of single fibers can be combined and mapped onto the elements representing bundle of fibers and ultimately representing this bundles of fibers in the nonwoven geotextiles. The cylindrical rod element is assumed as a straight bar, loaded at its ends with uniform properties from end to end. This type of elements has two degrees of freedom at each node, i.e., displacements in $X$ - and $Y$ - directions. Suitable equations are used at node points to describe the nonlinear behavior of the fibers. In the nonwoven geotextiles fibers are oriented in different directions, i.e., some fibers are in the machine direction, some fibers are in the cross-machine direction and other fibers oriented randomly. In the modeling work, these different fiber orientations are taking into account. The flow of incompressible non-Newtonian fluid through the pores of nonwoven geotextiles can be solved by Navier-Stokes equation ${ }^{15,16}$ along with Darcy's law. The Navier-Stokes equation for fluid flow is given by:

$$
\begin{gathered}
\rho \frac{\partial u}{\partial t}-\nabla\left[\eta\left(\nabla u+(\nabla u)^{T}\right)\right]+\rho(u \cdot \Delta) u+\Delta p=F \\
\nabla \cdot u=0
\end{gathered}
$$

where $\eta$ is the viscosity, $\rho$ is the density, $u$ is the velocity, $p$ is the pressure, and $F$ is the force. The first equation is the momentum balance equation, and the second is the equation of continuity for incompressible fluids.

\section{RESULTS AND DISCUSSION}

\section{Orientation distribution of fibers in nonwoven geotextiles}

A typical orientation distribution of fibers in the needle-punched nonwoven geotextiles (Samples A1 and A2; Table I) is shown in Figure 1. The vertical dashed arrow line at $90^{\circ}$ angle represents the machine direction, the cross direction being perpendicular to this. The lower frequency values in the machine direction indicate that fewer fibers are oriented in that direction. The higher frequencies values in the other direction indicates the majority of fibers are oriented in the cross direction, which is due to cross-lapping process of laying the web. Similar trend is also found for the other sample (A3) and is not shown here.

\section{Pore size and water permeability behavior of nonwoven geotextiles}

The pore size of needle-punched nonwoven geotextiles obtained from liquid extrusion porometry is shown in Table I. As the depth of needle penetration increases during the needle punching process, there is decrease in smallest, mean flow and maximum pore diameters. As the needling depth increases, frictional contact between the fibers increases as more number of needles acting on any fiber and consequently over the whole fabric area. As a result of this, there is more consolidation of the web and the web thickness decreases. So the nonwoven geotextile produced with less depth of needle penetration is consequently an open structure and is of the highest thickness (Sample A1) in comparison with the one which is produced with higher depth of needle penetration, which is less open, and thickness of the geotextiles is the lowest (Sample A3). There is decrease in smallest and maximum detected pore diameter with the increase in needle depth, as pores may be getting covered by the neighboring fibers.

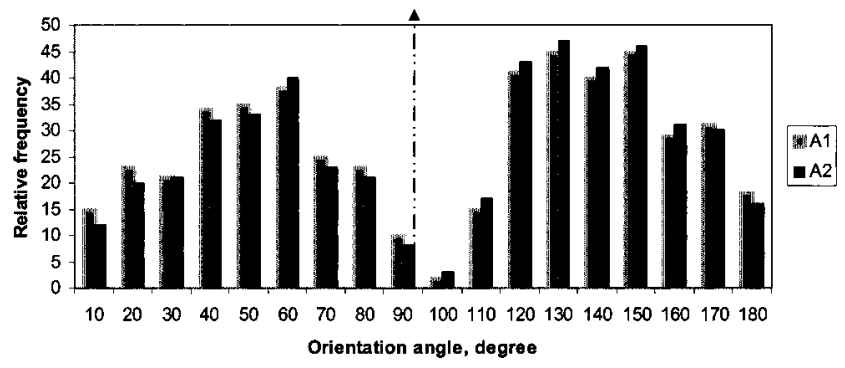

Figure 1 Orientation distribution of fibers in the needle punched nonwoven geotextiles. 


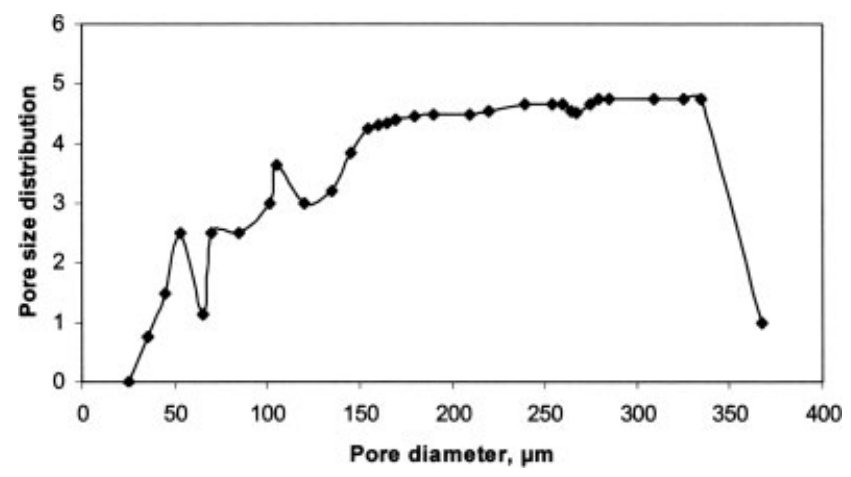

Figure 2 Pore size distributions obtained from liquid extrusion porometry for Sample A1.

There is $24 \%$ decrease in mean flow diameter with the increase in depth of needle penetration, the diameter of which is normally a measure of the size of the majority of pores. This may be due to the web getting more compact with the increase in needle depth as frictional contact between the fibers increases.

The pore size distributions of needle punched nonwoven geotextiles obtained from liquid extrusion porometry are shown in Figures $2-4$. We divided the pore size distribution into three different regions of pore diameters i.e., $0-100 \mu \mathrm{m},>100-250 \mu \mathrm{m}$, and $>250 \mu \mathrm{m}$. The percentage contribution of pores in the above three different regions for Samples A1, $\mathrm{A} 2$, and $\mathrm{A} 3$ are as follows: 22,44 , and $34 ; 25,50$, and $25 \%$; and 26,55 , and $19 \%$. These values indicate that, when depth of needle penetration increases, there is decrease in percentage of bigger pores $(>250 \mu \mathrm{m})$, as bigger pores are getting covered by the neighboring fibers during entanglement of the fibers by the barbed needles. This indicates that needle punched web become more compact. These bigger pores $(>250 \mu \mathrm{m})$ mainly govern the permeability, as how easily the fluid pass through the structure without unnecessary pressure built-up is of importance. Also, as the depth of needle penetration increases, the percentage of smaller $(0-100 \mu \mathrm{m})$ and medium

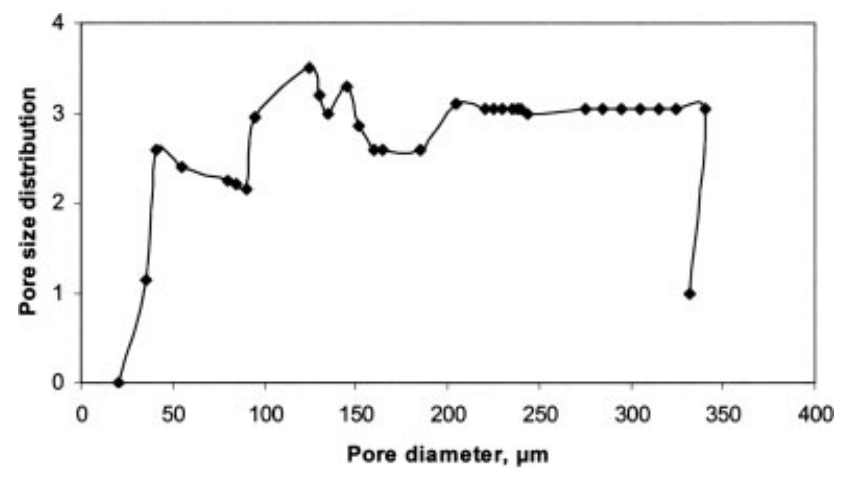

Figure 3 Pore size distributions obtained from liquid extrusion porometry for Sample A2.

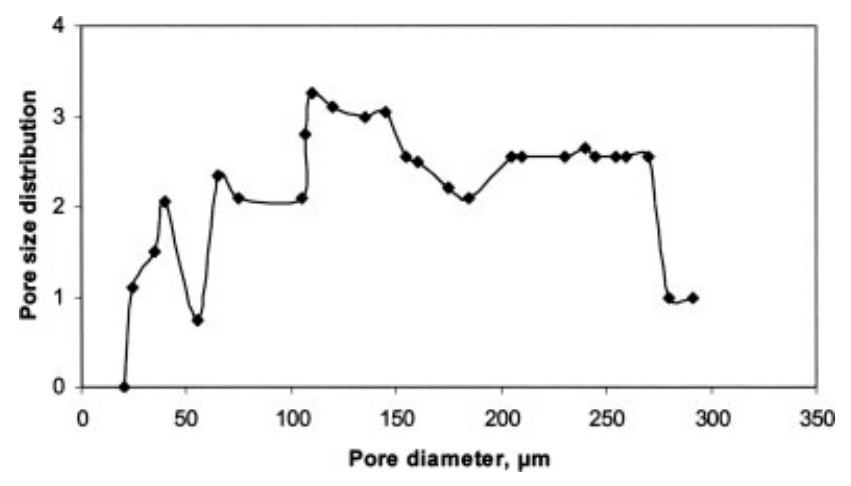

Figure 4 Pore size distributions obtained from liquid extrusion porometry for Sample A3.

pores $(>100-250 \mu \mathrm{m})$ increase. During the process of needle punching, some of the medium pores getting converted into smaller pores and bigger pores converted into medium pores due to the entanglement action of needle. The above types of pores mainly help in retaining the impurities in the fluid flowing apart from allowing the fluid to pass through it. In all geotextiles structures, pore size distribution obtained from experiment does not follow any definite trend as observed from Figures 2-4.

The water permeability behavior of needlepunched nonwoven geotextiles measured on a water permeability tester and corresponding average velocity values obtained from it and FEA are shown in Table I. The water permeability values of nonwoven geotextiles decreases as the depth of penetration of needles increases during the needle punching process. This may be due to variation in the pore characteristics of the three different nonwoven geotextiles. Although thickness of Sample A1 is higher compared with $\mathrm{A} 2$ and $\mathrm{A} 3$, it is the open structure among the three, followed by A2 and A3. Also mean flow pore diameter of Sample A1 is the highest among the three samples. So water passes easily through A1, than A2 and A3. The pore characteristics play an important role in the water permeability behavior. The velocity values of water $(\mathrm{mm} / \mathrm{s})$ flowing through the needle punched nonwoven geotextiles obtained from a 2D FEA is shown in Figure 5. The water flow through the nonwoven geotextiles is measured perpendicular to its plane. So, the fibers which are assumed as circular cylinder in the nonwoven geotextiles, when viewed from top, will look like a rectangular bar. Each color in Figure 5 represents a particular velocity value in $\mathrm{mm} / \mathrm{s}$, red being the highest and blue is the lowest. Each pore arises due to different arrangement of fibers, is represented by same or different colors of velocity values of water flowing through. The average velocity of water flowing through Samples A1 is the highest followed by $\mathrm{A} 2$ and $\mathrm{A} 3$, due to variation in the pore characteristics of the nonwoven geotextiles which 


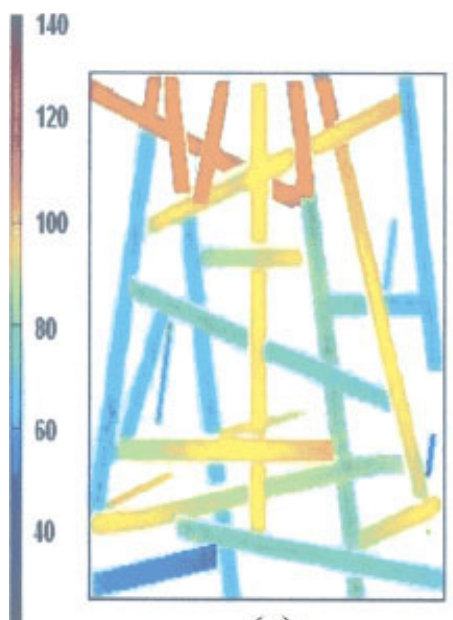

(a)

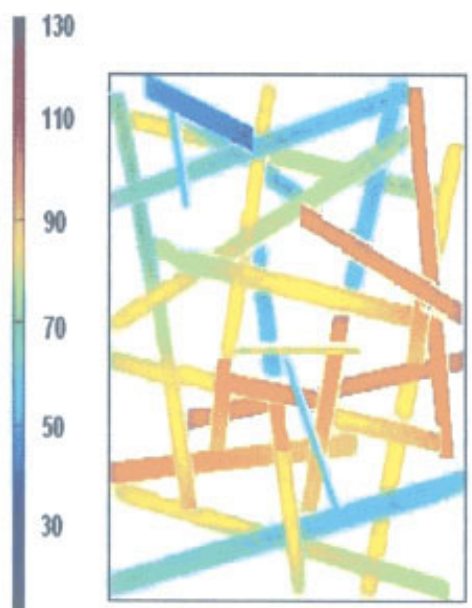

(b)

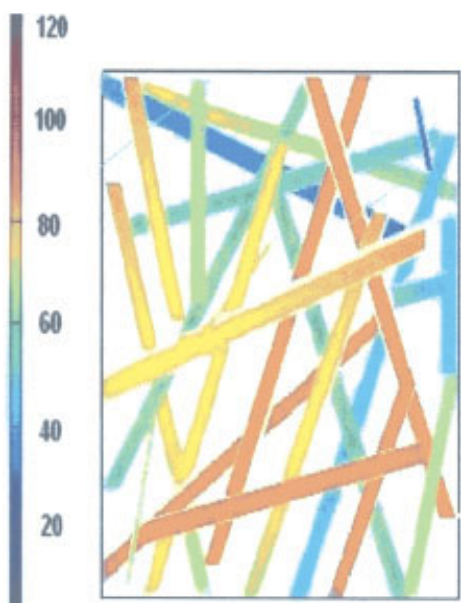

(c)

Figure 5 Velocity values of water (mm/s) through the needle-punched nonwoven geotextiles (a) A1, (b) A2, and (c) A3. [Color figure can be viewed in the online issue, which is available at www.interscience.wiley.com.]

subsequently governs the permeability behavior. Different pore sizes can be observed from the three different samples as the depth of needle penetration increases during the needle punching process (Fig. 5). The Sample A1 consists of a majority of bigger pores, in comparison with Samples A2 and A3, followed by medium and smaller pores. The Sample A3 mainly consists of medium and smaller pores and Sample A2 is in between of two samples. The average velocity values obtained from FEA is under evaluated. This may be due to the fact that, when observing the geotextiles from the top, some of the pores that are below the top layered may not get covered during this measurement, although the fabric thickness is very small. Another reason may be these pores have different configurations which may affect the results. Nevertheless, there is a good correlation between the average velocity values obtained from FEA and water permeability tester (Table I).

\section{CONCLUSIONS}

The influence of processing parameters during needle punching on the water permeability behavior of nonwoven geotextiles is investigated. The water permeability behavior is influenced by the arrangement of pores in nonwoven geotextiles. A theoretical prediction of cross-plane water flow through the nonwoven geotextiles was done by the FEA. A good correlation is achieved between the average velocity data obtained from water permeability test and theoretical prediction based on FEA.

\section{References}

1. Mao, N.; Russell, S. J. J Textile Inst 2000, 91, 235.

2. Mao, N.; Russell, S. J. J Textile Inst 2000, 91, 244.

3. Sullivan, R. R.; Hertel, K. L. J Appl Phys 1940, 11, 761.

4. Carman, P. C. Flow of Gases Through Porous Media; Academic Press: New York, 1956.

5. Cox, R. G. J Fluid Mech 1970, 44, 791.

6. Darcy, H. Les Fontaines Publiques de la Ville de Dijon; Victor Dalmont: Paris, 1856.

7. Patnaik, A.; Rengasamy, R. S.; Kothari, V. K.; Ghosh, A. Wetting and Wicking in Fibrous Materials; Textile Progress; Woodhead Publishing: Cambridge, UK, 2006.

8. Mao, N.; Russell, S. J.; Pourdeyhimi, B. In Russell, S. J., Eds.; Woodhead Publishing: Cambridge, UK, 2007.

9. Comsol Multiphysics 3.2. User Guide; COMSOL AB: Sweden, 2005.

10. EN ISO 11058. Geotextiles and Geotextiles-Related Products. Determination of Water Permeability Characteristics Normal to the Plane without Load; 1999.

11. Capillary Flow Porometer. Instruction Manual; Porous Material Inc.: USA, 2005.

12. Jena, A. Gupta, K. Int Nonwoven J 2003, 12, 45.

13. Mayer, E. Filtration News 2002, 20, 1.

14. Patanaik, A.; Anandjiwala, R. D.; Gonsalves, J.; Boguslavsky, L. Paper Presented in Finite Element Modeling of Textiles and Textile Composites Conference, St-Petersburg, Russia, September 26-28, 2007.

15. Gresho, P. M.; Sani, R. L. Incompressible Flow and the Finite Element Method; Wiley: New York, 2000; Vols. 1 and 2.

16. Pironneau, O. Finite Element Methods for Fluids; Wiley: New York, 1989. 